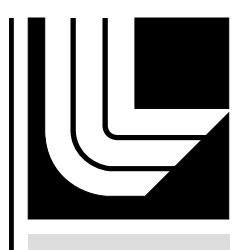

LAWRENCE LIVERM ORE N A TIO NAL LABORATORY

\title{
Proliferation Resistant Nuclear Reactor Fuel
}

L. W. Gray, K. J. Moody, K. S. Bradley, H. E. Lorenzana

June 3, 2011 
This document was prepared as an account of work sponsored by an agency of the United States government. Neither the United States government nor Lawrence Livermore National Security, LLC, nor any of their employees makes any warranty, expressed or implied, or assumes any legal liability or responsibility for the accuracy, completeness, or usefulness of any information, apparatus, product, or process disclosed, or represents that its use would not infringe privately owned rights. Reference herein to any specific commercial product, process, or service by trade name, trademark, manufacturer, or otherwise does not necessarily constitute or imply its endorsement, recommendation, or favoring by the United States government or Lawrence Livermore National Security, LLC. The views and opinions of authors expressed herein do not necessarily state or reflect those of the United States government or Lawrence Livermore National Security, LLC, and shall not be used for advertising or product endorsement purposes.

This work performed under the auspices of the U.S. Department of Energy by Lawrence Livermore National Laboratory under Contract DE-AC52-07NA27344. 


\section{Proliferation Resistant Nuclear Reactor Fuel}

\section{By}

Leonard W. Gray, Kenton J. Moody, Keith S. Bradley, and Hector E. Lorenzana 


\section{Introduction and Summary}

With the end of the cold war, there have been profound changes in the global security relationships. As a result, the proliferation risk associated with nuclear energy has become a focus of international discussions; the concerns regarding proliferation risks pose formidable challenges ${ }^{1}$. Nuclear energy has demonstrated the potential to help meet the rising energy demands, which are explosively growing in Asia, while at the same time reduce pollution emissions into the atmosphere ${ }^{2}$ - including carbon dioxide, carbon monoxide, sulfur dioxide, nitrogen oxides, volatile organic compounds, and heavy metals ${ }^{3}$ (mercury, arsenic, lead, cadmium, and uranium).

The primary risks of the nuclear fuel cycle in regards to proliferation are:

- Diversion of weapons usable material by nations ${ }^{4}$

- Diversion of weapons usable material by terrorist $/$ theft $^{5}$

\footnotetext{
${ }^{1}$ Indeed, the prospects for dramatic growth in nuclear power may depend on the effectiveness of and resources devoted to plans to develop and implement technologies as well as approaches that strengthen proliferation resistance. Although there are no approaches that can wholly eliminate the risk of proliferation by a determined state, eliminating many non-state threats [Pilat 2009]. tons of coal in 2020. As a result of its reliance on fossil fuels, China

has 16 of the 20 most air-polluted cities in the world. According to the World Health Organization, approximately 2,000,000 premature deaths occur annually worldwide due to air-pollution. Approximately 656,000 Chinese citizens each year die prematurely due to outdoor air pollution; polluted drinking water kills another 95,000. In addition, the World Health Organization estimates that Chinese suffer approximately 75,155,000 asthma attacks per year as the result of air pollution.

${ }^{3}$ A typical coal-fired power plant in China is estimated to annually produce:

- $\quad 3,700,000$ tons of $\mathrm{CO}_{2}$

- 10,000 tons of $\mathrm{SO}_{2}$

- 500 tons of small airborne particles

- 10,200 tons of $\mathrm{NO}_{\mathrm{X}}$

- 720 tons of CO

- 220 tons of toxic volatile organic compounds

- 170 pounds of mercury

- 225 pounds of arsenic

- 114 pounds of lead

- 4 pounds of cadmium

- Other toxic heavy metals

- Trace amounts of uranium
} technology can play a limited though very valuable role in reducing state threats and perhaps in

${ }^{2}$ At the present rate of building coal-fired power plants, China is projected to consume 3.2 billion

${ }^{4}$ There are a total of 52 countries with nuclear-related technical capabilities. This report deals only with the technology required to separate and purify plutonium should a state or sub-national group obtain a source of plutonium. The analysis of intention is open to a great deal of uncertainty and interpretation and is outside the scope of this study.

${ }^{5}$ There is a clear recognition that the threats posed by non-state networks and terrorists must be dealt with, if the promise of nuclear energy is to be realized [Pilat 2009]. 
Potential proliferators may gain access to nuclear materials at various points within the nuclear fuel cycle. Today there are two main nuclear fuel cycles:

- Once-through, in which the main steps are uranium enrichment, fuel fabrication, reactor irradiation, and storage with the presumption that the used fuel will eventually be disposed of in a repository.

- Recycling, in which the main steps are enrichment, fuel fabrication, reactor irradiation, short term storage, and reprocessing followed by:

○ Re-enrichment of the uranium and fabrication into new fuel elements for reactor irradiation ${ }^{6}$ and

- Storage of the plutonium oxide until fabricated into MOX fuel elements for reactor irradiation.

The first and most important attribute of a proliferant's potential to produce nuclear weapons is access to fissile material. To produce weapons-grade materials, a state needs to be able to either enrich uranium to weapons-grade (as Pakistan did and as Iran is apparently capable of doing should it choose to) or it needs to be able to recover plutonium from spent research reactor fuel (as North Korea did).

There are six different uranium enrichment technologies: gaseous diffusion, centrifuge enrichment, electromagnetic isotope separation, chemical and ion exchange enrichment, aerodynamic isotope separation, and laser enrichment (as developed by Lawrence Livermore National Laboratory). The three reactor types ${ }^{7}$ that have been used to produce weapons-grade plutonium are:

- Graphite moderated reactors (e.g., Hanford, Tomsk, North Korea, etc.)

- Heavy water moderated reactors (e.g., Savannah River, India, etc.)

NOTE: In principle, any research reactor is capable of producing at least some plutonium, but the quantity that can be produced depends strongly on the reactor power. Only research reactors with a capacity greater than about $10 \mathrm{MW}_{\mathrm{t}}$ can produce an amount that is generally considered sufficient to support an indigenous nuclear weapons effort.

A separations/reprocessing capacity must be developed for a state to be able to develop plutonium bomb program. These capabilities are fairly difficult to achieve because export controls and International Atomic Energy Agency (IAEA) safeguards carefully monitor both the raw materials and the technologies associated with special

\footnotetext{
${ }^{6}$ The spread of uranium enrichment technology as a result of the A. Q. Khan network has highlighted the risks from highly enriched uranium. Given the difficulty of detecting clandestine gas centrifuge facilities, one must question the proliferation resistance of once-through fuel cycles that require increasing enrichment capability if nuclear power grows as expected, with an even wider spread of enrichment technology worldwide [Pilat 2009].

${ }^{7}$ Any power reactor can be used to produce weapon-grade plutonium. It is just necessary to pull the fuels rods early. Approximately five tons of near weapons-grade plutonium is under the International Energy Atomic Energy Agency Safe-Guards program as a result of fuel rods being pulled early. Most of these fuel rods were pulled early because of leakage while in the reactor.
} 
nuclear materials. However, despite the fact that North Korea joined the IAEA in September 1974, signed an INFCIRC/66-type agreement on July 20, 1977 (this provided a mechanism to monitor some of their facilities), and acceded to the NPT in December 1985, North Korea began the construction of the so-called "radiochemical laboratory" some time between 1985 and $1987 .{ }^{8}$ By late 1988, US satellite imagery detected what was suspected to be a nuclear reprocessing facility under construction near the $25 \mathrm{MW}_{\mathrm{t}}$ reactor at Yongbyon. Since that time, North Korea has not only processed plutonium from the $25 \mathrm{MW}_{\mathrm{t}}$ reactor, ${ }^{9}$ but has also apparently exploded two test devices. North Korea has shown that, if a state has the political will, it can build and operate plutonium-processing facilities.

Similarly, any subnational group that wishes to recover plutonium for even a few weapons from stolen spent fuel must also develop a separation/reprocessing capacity. However, it should not be assumed that a subnational group would follow the lead of developed national bomb program and build massive structures to recover and purify the plutonium. Neither should it be assumed that a subnational group would use the widely used Purex Process to recover and purify the plutonium.

In its race to build the bomb, the United States used a precipitationbased method, the Bismuth Phosphate process, to recover and purify the plutonium used in early weapons. ${ }^{10}$ In its quest for the bomb, the Soviets also used a precipitation process until about 1972, a modification of the sodium uranyl acetate analytical procedure, to recover and purify plutonium. Most, if not all of the British plutonium, was recovered and purified via the Butex (not Purex) Process. France independently developed its own version of Purex which included a Carbonate precipitation step.

Neither should it be assumed that a subnational group would recover and purify both the plutonium and the uranium.

In its quest for the bomb, the United States did not even attempt to recover the uranium in the early days of it nuclear program. North Korea separates the uranium and plutonium, but then only stores the uranium solution, perhaps to be purified at a later date.

Given this analysis, we conclude that all of the relevant and commonly used processing options available to a subnational group need to be addressed to effectively enhance the proliferation resistance of fuel. Specifically, we need to be aware that countermeasures that would make it more difficult to process via one

\footnotetext{
${ }^{8}$ The facility is 600 feet in length, 65 feet wide, and several stories high, about the size of two football fields.

${ }^{9}$ This indigenous experimental reactor was patterned after the declassified prints of the 1940's vintage Calder Hall gas-graphite reactor (an English MAGNOX reactor).

${ }^{10}$ To save time, Du Pont elected to go forward with building the plutonium processing facility assuming that the selected process would be a precipitation process based upon the fact that most industrial separations processes at the time were based upon precipitation. The equipment for these industrial processes was fairly simple, and the steps could be repeated several times, if necessary, in the same equipment.
} 
method might not interfere at all with another method. To date, most developed processes have used a nitric acid solvent to dissolve the spent fuel or target. This is an excellent choice, but other aqueous solvents or even non-aqueous solvents such as molten metals or salts can be used.

In general, there are four measures [Kibriyama 2000] that that can be used to enhance the proliferation resistance ${ }^{11}$ of the fuel:

- Self-Protection aspects of the material: Characteristics of the material that can complicate gaining physical control of a significant quantity of the weapons usable material. (Measures such as: $\mathrm{rad} / \mathrm{hr}$ at 1 meter, number of items for 1 significant quantity, etc.)

- Physical form. (Measures such as: size, weight, and radioactivity)

- Technical difficulty of processing. (Measures such as concentration of plutonium and chemical form especially the difficulty of dissolution in an appropriate processing medium.)

- Time of Processing. (Measures such as time to process 1 significant quantity)

\section{Proliferation Resistance Overview}

The term proliferation resistance has been in use in regards to the nuclear fuel cycles since the 1950's [Feiveson 1979; Kibriyama 2000]. Numerous scientists have made proposals for proliferation resistant technologies over the past 30 to 40 years with specifications as to what proliferation resistance means to them. However, there is not common understanding as to exactly what proliferation resistant technology entails.

The IAEA defines proliferation resistance as follows:

Proliferation resistance is that characteristic of a nuclear system that impedes the diversion or undeclared production of nuclear material or misuse of technology by states in order to acquire nuclear weapons or other nuclear explosive devices.

In this analysis, we expand this often used definition of proliferation resistance by including the implementation of measures that would impede the successful exploitation of stolen nuclear materials by terrorists or other subnational groups for nuclear explosives.

The proliferation resistance of any plutonium form is determined by:

- The physical form of the material;

- The physical access afforded to the material;

\footnotetext{
${ }^{11}$ Proliferation deterrence involve efforts to increase the technical difficulty as well as cost and time that is needed by the proliferators. In most cases the impact will be most effective if a state proliferators are not technologically advanced; the impact of proliferation resistance on non-state actors can be far more significant [Pilat 2009].
} 
- The level of safeguards ${ }^{12}$ and security that are applied to the material; and

- The national/subnational threat to the material.

All of these factors affect the resources and technical complexity for acquiring, transporting, and processing the material for use in a nuclear weapon. The degree of proliferation resistance results from a combination of, inter alia, technical design features, operational modalities, institutional arrangements and safeguards measures. This document does not deal with safeguards, security, or transportation. It also makes the assumption that the clandestine national/subnational group has obtained:

- A source of plutonium;

- That it has obtained the technology and required equipment to recover and purify the plutonium and then to fabricate a weapon; and

- It has at least the explicit knowledge and expertise ${ }^{13}$ to recover and purify the plutonium and then to fabricate a weapon should it so desire.

The Department of Energy (DOE) assigns attractiveness levels to the various forms of plutonium according to the amount of processing required to obtain weapons-usable material. These levels in order of decreasing attractiveness are:

1. Assembled weapons and test devices;

2. Directly convertible materials such as pits, buttons, and ingots;

3. High grade materials such as oxides, carbides, and nitrides;

4. Low-grade materials such as process residues; and

5. Highly irradiated forms.

Again, the first four DOE levels of attractiveness are outside the scope of this report. This report deals only with methods to attempt to render spent reactor fuel more proliferation resistant.

The form of the material in terms of its radiological, chemical, and physical characteristics affect the difficulty of processing the material for use in a nuclear explosive. At present there are over 400 reactors operating worldwide. Many of these reactors are having their licenses renewed for operation for another 20 to 40 years. New reactors being proposed are basically advanced versions of reactors now in operation. As a result, the basic fuel forms will not be radically changed for at least the next 40 to 60 years. Therefore, proliferation resistance of the fuel will be most likely limited to radiological and chemical makeup of the spent fuel.

\footnotetext{
${ }^{12}$ The objective of safeguards is the timely detection of diversion of significant quantities of nuclear material from peaceful nuclear activities to the manufacture of nuclear weapons or of other nuclear explosive devices or for purposes unknown and deterrence of such diversion by the risk of early detection.

${ }^{13}$ Knowledge can be broadly categorized as explicit and tacit. Explicit knowledge includes technical information in the form of scientific research, engineering analysis, design documentation, operational date, maintenance records, regulatory reviews and other documents and data that can be transferred easily to interested parties. However, documents never comprise the expert's complete knowledge, and the novice reading those instructions might not end up with the same results as the expert. The tacit knowledge of the experts, including scientist, engineers, and technicians, is acquired over long period and my never be fully articulated.
} 
Before spent reactor fuel can be used in weapons, it must be purified to remove both the fission products and the non-fissile parts of the fuel element. A number of methods have been used to recover and purify plutonium to support a state atomic bomb program. The most widely used method is the Purex Process [Purex Process 1977]. Other solvent extraction processes, e.g., Redox, Butex and Trigly, have also been used. Precipitation methods such as the sodium uranyl acetate precipitation process (used by the Soviets), the bismuth phosphate precipitation process (used by the United States), and carbonate precipitation process (used by France) were developed and used for short cooled fuel. However, it is not necessary to assume that a subnational group would choose to use short cooled fuel to be the source of plutonium for a few weapons. The commercial spent fuel-reprocessing program allows fuel to cool for at least four years prior to processing. The short-lived fission products, that necessitate short contact times in processing via aqueous/solvent separations methods, have decayed away during this cooling time. Without the necessity of short contact times, anion exchange becomes a very viable method to recover and purify plutonium for a small bomb program. $^{14}$

The overall goal of producing proliferation resistant fuel is to impede the diversion of special nuclear materials from civilian nuclear power spent fuel that could be used in the production of weapons. But, as can be seen from the above discussion, a number of different process parameters must be considered when addressing this problem. In addition, a credible nuclear threat from a sub-national group is different than that from a proliferant state. The perceived threat from a sub-national group is more dependent upon device producing any nuclear yield than it is upon the actual amount of yield. Even in a low technology, low quality device, any nuclear yield will, in most cases, vastly exceed that of conventional explosive device. Thus, any device capable of generating a nuclear yield would meet the requirements of a sub-national group. A proliferant state is more likely to have preference for materials that are more easily and efficiently fabricated into higher and more reliable yield nuclear weapons than those materials of interest to a sub-national (terrorist) group [Bathke 2009].

Some proposals suggest adding something to the fuel that would make the resulting plutonium non-useable for weapons. However, because of the unique aqueous-nitrate chemistry of plutonium, the most difficult elements to remove from plutonium are uranium, neptunium, and thorium; these four elements form neutral and/or anionic complex ions with nitrate ions; other elements do not form these complex ions.

- As a result of these neutral and anionic complex ions, in one pass of either solvent extraction or anion exchange, a uranium feedstock containing only a few hundred-parts-per-million plutonium can be purified to a few tens-of-parts-permillion uranium in the plutonium.

- Plutonium-238 is routinely separated via anion exchange, on the kilogram scale, from ${ }^{237} \mathrm{~Np}$ reactor targets.

- Although plutonium and thorium are not generally produced together in a reactor, their separation requires very little modification of the standard solvent extraction or anion exchange processes.

\footnotetext{
${ }^{14}$ The required equipment is much simpler (primarily tanks, pipes and filters) for anion exchange process than solvent extraction process.
} 
Therefore, addition of any element to low enriched fuel to render the processed plutonium non-weapons usable, other than perhaps the minor actinides ${ }^{237} \mathrm{~Np}$ and ${ }^{241} \mathrm{Am}$ that generate ${ }^{238} \mathrm{Pu}$ upon irradiation in a reactor, is futile. Adding ${ }^{237} \mathrm{~Np}$ and ${ }^{241} \mathrm{Am}$ to $\mathrm{MOX}$ fuel would increase the content of weapons undesirable isotopes, namely ${ }^{238} \mathrm{Pu},{ }^{240} \mathrm{Pu}$ and ${ }^{242} \mathrm{Pu}$, while further decreasing the combined content of the weapons-desirable fissile isotopes ${ }^{239} \mathrm{Pu}$ and ${ }^{241} \mathrm{Pu}$. Depending upon the level of burn-up, the plutonium in spent fuel may be as high as $8 \%{ }^{238} \mathrm{Pu}$, according to Bathke et al. [Bathke 2009]. Adding addition $\mathrm{Pu}$ further reduces the attractiveness of the plutonium for use in nuclear weapons. For a subnational group in which any nuclear yield is acceptable, $80 \%{ }^{238} \mathrm{Pu}$ is required to reduce the plutonium to "low" attractiveness. For an unadvanced proliferant nation in which a high yield reliable nuclear device is desirable, very little additional ${ }^{238} \mathrm{Pu}$ is required to lessen the plutonium attractiveness level.

From the stand point of theft of spent fuel by a terrorist group, it might be possible to enhance the radiation dose for a longer period of time - i, e., increase the time that the spent fuel is self-protecting. However, to be considered an effective deterrent to theft, a self-protecting characteristic must demonstrate its effect within a relatively short time period, according to Coates, et al. [Coates 2005]. Isotopes that have been suggested in the past include ${ }^{197} \mathrm{Au},{ }^{81} \mathrm{Ta},{ }^{64} \mathrm{Zn},{ }^{59} \mathrm{Co}$, and ${ }^{231} \mathrm{~Pa}$. Of these isotopes, only ${ }^{231} \mathrm{~Pa}$ perhaps yields any value added. However, Coates seems to question whether or not self-protection from a committed terrorist entity really does exist.

From a practical processing viewpoint, the purification of plutonium requires that it be brought into solution (aqueous, molten salt, or molten metal), so any approach that would prevent or cause difficulty exposing the fissile material to the processing solution or increase the difficulty of dissolution would be valuable in preventing the use of plutonium in a weapon. However, it should be clear that hindering the dissolution processes would render recovery and purification more difficult but not impossible. Likewise, adding a component that either would not dissolve or would emulsify the solvent would interfere with the processing via solvent extraction. Examples of oxides of elements that would not interfere with the operation of the reactor but would increase difficulty of separations are $\mathrm{Al}_{2} \mathrm{O}_{3}, \mathrm{ZrO}_{2}$ and $\mathrm{TiO}_{2}$; a burnable poison that might be added is $\mathrm{HfO}_{2}$. If sufficient $\mathrm{ZrO}_{2}$ or $\mathrm{HfO}_{2}$ could be added to yield a ceramic fuel that was very difficult to dissolve, then the difficulty of processing could be markedly increased. However, once the plutonium and uranium were dissolved, removal of these from the solutions via standard industrial practices would be relatively easy.

A corollary to this would be to add something whose activation product would yield a gas upon dissolution. In the production of weapons grade plutonium, the spent fuel or targets are cooled for over 140 days to allow the ${ }^{\mathrm{I} 31} \mathrm{I}$ (half-life 8.05 days, i.e. $>17$ half-lives) to decay away. Additionally, silver filters are used in the off-gas stream to capture the remaining ${ }^{\mathrm{I} 1} \mathrm{I}$. Control is maintained on the nitrite concentration of the dissolver medium to prevent the oxidation of ${ }^{\mathrm{I} 03} \mathrm{Ru}$ (half-life 40 days; 140 days is $>3$ half-lives) to gaseous ${ }^{103} \mathrm{RuO}_{4}$. Although not a fission product of value, bismuth could be added to the fuel; upon irradiation, bismuth yields ${ }^{210} \mathrm{Po}\left[{ }^{209} \mathrm{Bi}(\mathrm{n}, \gamma){ }^{210} \mathrm{Bi} \rightarrow{ }^{210} \mathrm{Po}\right]$. Upon dissolution, ${ }^{210} \mathrm{Po}$ would yield a poisonous, volatile compound. Unfortunately, ${ }^{210} \mathrm{Po}$ only has a 130-day half-life. Cooling the fuel for 260 days would reduce the ${ }^{210}$ Po by $75 \% ; 390$ days would reduce the ${ }^{210}$ Po by $87.5 \%$; 520 days would reduce the ${ }^{210}$ Po by $93.75 \%$. This would increase the "self-protection" from gaseous products slightly, but not significantly. 
(Spent fuel that is being processed today is cooled a minimum of 4 years (1460 days) or over 11 half-lives of ${ }^{210} \mathrm{Po}$; hence $99.99 \%$ of the ${ }^{210} \mathrm{Po}$ would have decayed away.)

\section{Discussion of Self-Protecting Fissile Materials From a Physics Perspective}

Self-Protecting Spent Fuel. The IAEA considers spent fuel to be self-protecting if the radiation rate exceeds $1 \mathrm{~Gy} / \mathrm{hr}(1 \mathrm{~Sv} / \mathrm{hr} ; 100 \mathrm{rad} / \mathrm{hr})$ at one meter in air (unshielded). [Kang 2005; INFCIRC/225/Rev.4 1979; Pond 1996].

Current guidance considers highly radioactive special nuclear material (SNM) to be those materials that unshielded, emit a radiation dose rate of measured at 1 meter that exceed 100 rem per hour. Both DOE and IAEA used this definition. The basis for this number is as follows: A 350 rem absorbed dose is the mid-point of the 250- to 450-rem range generally accepted as the dose in which $50 \%$ the exposed people would be expect to die, $50 \%$ lethal dose $\mathrm{LD}_{50}$. Based on this, highly radioactive SNM's are considered to be those materials that will deliver a 350-rem dose in 3 hours, which was rounded to $100 \mathrm{rem} / \mathrm{hr}$. Although a 350-rem dose is considered lethal for $50 \%$ of the people, the immediate health effects are minimal vomiting (emesis) with onset sometimes . between 0.5 and 16 hours after exposure. The delay to onset of emesis (especially when added to the three-hour exposure period) allows a substantial amount of time in which exposed personnel can function, even if at a reduced effectiveness (see Table I) to complete a task.

\begin{tabular}{|c|c|}
\hline $\begin{array}{r}\text { Table I. Assumed stepwise decline in } \\
\text { efficiency with increasing } \\
\text { cumulative dose }\end{array}$ \\
\hline Dose(Gy) & Efficiency \\
\hline$<25$ & 1.0 \\
\hline $25-29$ & 0.6 \\
\hline $30-34$ & 0.5 \\
\hline $35-39$ & 0.4 \\
\hline $40-44$ & 0.3 \\
\hline $44-49$ & 0.2 \\
\hline $50-100$ & 0.1 \\
\hline$>100$ & 0.0 \\
\hline
\end{tabular}

Obviously, a terrorist could work for hours in a 100 rad field prior to showing any signs of radiation sickness (possibly nausea or vomiting). In light of worldwide terrorist events that graphically demonstrate the resolve of perpetrators and their disregard for self-preservation, it seems reasonable and prudent to consider that terrorists will be willing to expose themselves potentially to lethal levels of radiation. Therefore, one must question whether self-protection is possible against committed terrorist [Coates 2005]. 
Six fission product pairs, ${ }^{90} \mathrm{Sr}-{ }^{90} \mathrm{Y},{ }^{95} \mathrm{Zr}-{ }^{95} \mathrm{Nb},{ }^{106} \mathrm{Ru}-{ }^{106} \mathrm{Rh},{ }^{133} \mathrm{Cs}-{ }^{134} \mathrm{Cs}$, ${ }^{137} \mathrm{Cs}-{ }^{137 \mathrm{~m}} \mathrm{Ba}$, and ${ }^{144} \mathrm{Ce}-{ }^{144} \mathrm{Pr}$, contribute the majority of the dose to spent fuel. Of these twelve fission products, only ten actually contribute to the dose rate. While not photon emitters, ${ }^{106} \mathrm{Ru}$ and ${ }^{134} \mathrm{Cs}$ are included since they are the precursors of ${ }^{106} \mathrm{Rh}$ and ${ }^{134} \mathrm{Cs}$; the direct product production of the ${ }^{106} \mathrm{Rh}$ and ${ }^{134} \mathrm{Cs}$ isotopes is small. With few exceptions, the primary fission product isotopes, which render the spent fuel selfprotecting, have half-lives of one year or less. Hence by the time fuel has been cooled for four years, most of the "hot" isotopes have passed through four to $>100$ half-lives. Specific examples include ${ }^{3} \mathrm{Ru},{ }^{144} \mathrm{Ce}$, and ${ }^{106} \mathrm{Ru}$, that have a half-live of 40 days, 0.8 years, and 1 year, respectively. Hence the two fission product pairs ${ }^{90} \mathrm{Sr}-{ }^{90} \mathrm{Y}$ and ${ }^{137} \mathrm{Cs}-{ }^{137 \mathrm{~m}} \mathrm{Ba}$ are the primary dose rate contributors after a few years of fission product decay, with ${ }^{137} \mathrm{Cs}$ and ${ }^{90} \mathrm{Sr}$ having half-lives of 30 and 20 years, respectively.

Fission product productions are, of course, proportional to the amount of fissile material in the fuel and the burn-up. The most important factors are:

- The mass of ${ }^{235} \mathrm{U}\left(\right.$ or $\left.{ }^{239} \mathrm{Pu}\right)$ burned

- The percentage of ${ }^{235} \mathrm{U}$ (or ${ }^{239} \mathrm{Pu}$ ) burned

- The time averaged specific power density

Depending upon the various factors, Argonne [Pond 1994; Pond 1996] has calculated the effectiveness of self-protection of various fuels to vary from as little as two years to greater than 20 years. These papers assumed the IAEA self-protecting value of $1 \mathrm{~Sv} / \mathrm{hr}$, $100 \mathrm{rem} / \mathrm{hr}$. For example, in a MTR-type fuel-assemble with $40 \%$ burn-up that initially contained $280 \mathrm{~g}$ of ${ }^{235} \mathrm{U}$, the mass of ${ }^{235} \mathrm{U}$ burned is $112 \mathrm{~g}$. If irradiated at a time-average power density of $0.089 \mathrm{MW} / \mathrm{kg}^{235} \mathrm{U}(0.025 \mathrm{MW})$, this fuel assemble would be selfprotecting for a maximum of 6 years after discharge from the reactor. At 2.857 $\mathrm{MW} / \mathrm{kg}^{235} \mathrm{U}(0.8 \mathrm{MW})$, the self-protection would increase to approximately 9 years after reactor discharge. To increase the number of self-protecting years at a given power density, the fuel assembly burn-up would need to be increased. An increase in burn-up to $60 \%\left(168 \mathrm{~g}{ }^{235} \mathrm{U}\right.$ burned) would increase the minimum number of self-protecting from about 15 years to more than 20 years for the range of power densities from 0.089 to 2.857 $\mathrm{MW} / \mathrm{kg}^{235} \mathrm{U}$ [Pond 1994]. 
The last reprocessing of commercial spent fuel in the United States occurred around 1968, when the West Valley Plant was shut down. Although detailed calculations have not been made, when considering that the average burn-up of spent fuel in the USA historically has ranged from $\sim 15 \mathrm{MW}-\mathrm{d} / \mathrm{kg}$ for BWR spent fuel and from $\sim 25 \mathrm{MW}-\mathrm{d} / \mathrm{kg}$ for PWR's to present day values of $45-50 \mathrm{MW}-\mathrm{d} / \mathrm{kg}$ [Bathke 2009], it is safe to assume that perhaps half or more of the spent fuel in the United States today is no longer self-protecting, utilizing the 100-rad/hr definition. Assuming the more realistic 500-rad/hr-dose rate, perhaps all of the fuel discharged prior to about 2004 or 2005 is no longer self-protecting.

Another theoretical method that may be used to make spent fuel more proliferation resistant is to add an element to the fuel meat whose irradiation product would raise the radiation dose of the plutonium product above the low (1 Sv/hr) IAEA threshold for self-protecting. A variety of elements whose neutron activation products are highly active are potential candidates for this scheme. The half-lives would have to be long enough, yet short enough, to provide a high dose over an extended period of time. Isotopes that have been proposed in the past include ${ }^{197} \mathrm{Au},{ }^{81} \mathrm{Ta},{ }^{64} \mathrm{Zn},{ }^{59} \mathrm{Co}$ and ${ }^{231} \mathrm{~Pa}$.

- Gold-198 (the neutron activation product of ${ }^{197} \mathrm{Au}$ ) with a half-life of 2.7 days, however, would provide a high dose for only a few days.

- Tantalum-182 (the neutron activation product of ${ }^{182} \mathrm{Ta}$ ) with a half-life of 115 days, however, would provide a high dose for a few months.

- Zinc-65 (the neutron activation product of ${ }^{64} \mathrm{Zn}$ ) with a half-life of 243.7 days, however, would provide a high dose for a year or two.

- Cobalt-60 (the neutron activation product of ${ }^{59} \mathrm{Co}$ ) with half-life of 5.259 years would provide additional radiation dose, at most, for a decade or so.

- Under neutron irradiation, ${ }^{231} \mathrm{~Pa}$ is converted into ${ }^{232} \mathrm{U} ;{ }^{232} \mathrm{U}$ decays with a 69 year half-life through 1.9 year half-life ${ }^{228} \mathrm{Th}$ to ${ }^{208} \mathrm{~T} 1$, which emits a $2.6 \mathrm{MeV}$ gamma ray upon decay. After 2 years of decay ${ }^{208} \mathrm{~T} 1$ accounts for about $85 \%$ of the total dose. Therefore, introduction of sufficient ${ }^{231} \mathrm{~Pa}$ to the fresh fuel might increase the time that the spent fuel is self-protecting to 100 years or more, under the 1 $\mathrm{Sv} / \mathrm{hr}(100 \mathrm{rad} / \mathrm{hr})$ definition of self-protecting.

Detailed calculations would have to be made to determine the amount of the precursor isotopes that would have to be added to yield enhanced protection. ${ }^{15}$ If such calculations were done, it is suggested that a minimum of the $500-\mathrm{rad} / \mathrm{hr}$-dose rate be assumed for the calculations. In the case of ${ }^{231} \mathrm{~Pa}$, a source search would have to be made to determine whether sufficient quantities of the isotope could be procured. The isotope is present in uranium ore, but traditionally ${ }^{231} \mathrm{~Pa}$ has not been recovered on any scale that would allow its used on an industrial scale.

\footnotetext{
${ }^{15}$ The high radiation levels that can provide a barrier to material theft, and perhaps make the material somewhat less attractive for weapons, can interfere with materials accounting and make safeguards measurements far more difficult. Moreover, they would likely also have adverse operational impacts on nuclear facilities, including increased costs [Pilat 2009].
} 


\section{Reducing the Strategic Value of the Plutonium}

Even though it requires a higher fissile content in the initial fuel and the addition of burnable poisons to control the reactivity in the beginning of the irradiation cycle, the present trend is toward higher and higher burn-ups in the LWR-MOX fuel cycles. This has two beneficial proliferation enhancements:

- The so-called self-protection time (at a dose of $>1 \mathrm{SV} / \mathrm{hr}$ ) is extended

- The ratio of weapons non-desirable plutonium isotopes $\left({ }^{238} \mathrm{Pu},{ }^{240} \mathrm{Pu}\right.$ and $\left.{ }^{242} \mathrm{Pu}\right)$ to weapons desirable isotopes $\left({ }^{239} \mathrm{Pu}\right.$ and $\left.{ }^{241} \mathrm{Pu}\right)$ is increased.

ORIGEN code calculations would give an indication of how the plutonium isotopic content changed with the higher burn-ups. Weapons design code calculations would be necessary to estimate the expected yield of any weapon fabricated from such

plutonium. Only then could a realistic determination be made as to the over all effect of the increased burn-up.

Another method to reduce the strategic value of a fuel element is to reduce the amount of plutonium produced by adding an element such a thorium; this would reduce the amount of plutonium generated by neutron capture. Thorium is fertile but it is not fissile. The activation product, however, is ${ }^{233} \mathrm{U}$, which is fissile. By adding a blend of ${ }^{238} \mathrm{U}$ and ${ }^{232} \mathrm{Th}$, the ${ }^{233} \mathrm{U}$ could be assured to be less than the threshold amount to produce a weapon, assumed to be $>20 \%{ }^{233} \mathrm{U}$. Having both ${ }^{238} \mathrm{U}$ and ${ }^{232} \mathrm{Th}$ to absorb the neutrons, would yield smaller amount of plutonium than just ${ }^{238} \mathrm{U}$ absorber in the reactor. Adding a few tens of $\mathrm{ppm}{ }^{231} \mathrm{~Pa}$ to the fuel would assure the production of ${ }^{232} \mathrm{U}$; this would assure that a very strong gamma would remain with the uranium should a terrorist group try to enrich the ${ }^{233} \mathrm{U}$ and then fabricate a weapon from the enriched ${ }^{233} \mathrm{U}$. The major impact of this option would be to increase the number of fuel elements that must be stolen to yield a significant quantity of plutonium. The added amount of processing required and the extra difficulty of processing fuel containing $\mathrm{Th}, \mathrm{U}$, and $\mathrm{Pu}$ would substantially increase the time required to recover and purify a significant quantity of plutonium.

Some Th-U fuel mixtures have been analyzed [Bathke 2009]. This analysis suggests that this cycle produces two isotopes of safeguards concern: ${ }^{233} \mathrm{U}$ bred from the thorium and ${ }^{239} \mathrm{Pu}$ bred from the low enriched, natural, or depleted uranium that is introduced to dilute the ${ }^{233} \mathrm{U}$ that is bred from the thorium. This study notes that smaller quantities of ${ }^{239} \mathrm{Pu}$ are produced than would be when burning uranium fuel. However, the case not studied was fabricating a MOX fuel of reactor grade plutonium, depleted uranium and thorium, perhaps with the addition of a small amount of protactinium. In general, when MOX fuel is burned in a reactor, plutonium is both burned and created. At the end of the cycle, the net increase in plutonium is zero. Therefore, burning a MOX fuel of reactor grade plutonium, depleted uranium and thorium should actually burn more plutonium than is created.

In addition to actually decreasing the amount of plutonium in the world, this fuel mixture would also have the following benefits:

- Decrease the amount of uranium that would have to be enriched 
- Decrease the amount of separated plutonium in storage under safeguards

- Return the plutonium to an unseparated, irradiated form

- Generate $\mathrm{a}^{233} \mathrm{U} /{ }^{238} \mathrm{U}$ mixture that was not weapons usable without enrichment

- If the ${ }^{231} \mathrm{~Pa}$ option were chosen:

- The spent fuel would be self-protecting for 50 to 100 years

- The generated ${ }^{232} \mathrm{U}$ would follow the ${ }^{233} \mathrm{U}$ in any enrichment scheme, assuring that the enriched ${ }^{233} \mathrm{U}$ would self-protecting for 50 to 100 years.

Plutonium-238. The IAEA considers plutonium containing greater than $80 \%$ ${ }^{238} \mathrm{Pu}$ to not require safeguards [INFCIRC/225/Rev.4 1979]. As the bare critical mass of $100 \%{ }^{238} \mathrm{Pu}$ has been calculated to be between 9.6 and $9.8 \mathrm{~kg}$ [Kang 2005; Wright 2000] and the gamma dose rate is only $6.09 \mathrm{mSv} / \mathrm{hr}-\mathrm{kg}$ (three orders of magnitude below the IAEA's threshold for self-protecting), the lack of the necessity for safeguards is the result of the heat released by the ${ }^{238} \mathrm{Pu}$. At a heat release of 568 $\mathrm{W} / \mathrm{kg}$ for ${ }^{238} \mathrm{Pu}$, a critical mass of ${ }^{238} \mathrm{Pu}$ metal would be far above the melting point of plutonium metal $\left(\sim 640^{\circ} \mathrm{C}\right)$. This amount of heat would also decompose any organic compounds in a matter of a few moments; hence high explosives (HE) could not be packed around the plutonium, even if the plutonium were in the oxide form.

Granted, if producing stockpile weapons with reliable yields were the goal of a proliferating nation, steps could perhaps be taken to remove the heat from plutonium containing high isotopic concentrations of ${ }^{238} \mathrm{Pu}$. A terrorist group, not interested in stockpile weapons with reliable yields, could delay arming the weapon to the last possible minute and therefore could perhaps tolerate a higher heat value. To make a definitive determination of how much ${ }^{238} \mathrm{Pu}$ would be necessary in the plutonium to render it useless would require extensive bomb code calculations that are outside the scope of this study. It is generally believed that approximately $80 \%{ }^{238} \mathrm{Pu}$ would be necessary. ${ }^{16}$ When burning plutonium, it appears that the maximum ${ }^{238} \mathrm{Pu}$ content would top out at about $20 \%{ }^{238} \mathrm{Pu}$. Thus denaturing plutonium by increasing the ${ }^{238} \mathrm{Pu}$ content would at most have a nuisance value.

Weapons-Grade Plutonium. The United States defines weapons grade plutonium as containing a ${ }^{239} \mathrm{Pu}$ content of $>92 \%$. Mark [Mark 1993] has published calculations, quoted by Kang and von Hippel [Kang 2005], showing that the dose rate from weapons-grade plutonium is about $8 \times 10^{-7} \mathrm{~Sv} / \mathrm{hr}-\mathrm{kg}$. This dose is about seven orders of magnitude below the IAEA's threshold for self-protecting. The thermal flux from weapons-grade plutonium is about 2.3 watts per $\mathrm{kg}$; this is far below the threshold to thermally decompose the organic high explosive packed around the plutonium pit. Hence, fabricating and storing stockpile weapons is possible.

Weapons-Grade Uranium. Weapons can be fabricated from highly enriched (fissionable) uranium-235. However, if the uranium is diluted with fertile but nonfissionable ${ }^{238} \mathrm{U}$ to a point that the ${ }^{235} \mathrm{U}$ is less than $20 \%$, then a weapon cannot be fabricated from the uranium without re-enriching it.

${ }^{16}$ To get $80 \%{ }^{\text {ZH8 }} \mathrm{Pu}$ requires irradiating a target of ${ }^{237} \mathrm{~Np}$ or ${ }^{241} \mathrm{Am}$. 


\section{Self-Protecting Summary From a Physics Perspective}

From the physics viewpoint, it appears that theoretically there are three basic methods to discourage a terrorist from trying to fabricate a weapon from stolen plutonium.

1. Maintain the dose rate at greater than $1 \mathrm{~Gy} / \mathrm{hr}(1 \mathrm{~Sv} / \mathrm{hr} ; 100 \mathrm{rad} / \mathrm{hr}$ at one meter in air.

This raises the possibility of adding an element to the fuel meat or the cladding whose irradiation product would lengthen the time where the radiation dose would be above the IAEA threshold for selfprotecting.

In light of worldwide terrorist events that graphically demonstrate the resolve of the perpetrators and their disregard for self-preservation, it seems reasonable and prudent to consider that terrorist will be willing to expose themselves to extreme (lethal) levels of radiation [Coates 2005]. It would therefore seem that this option would have a limited effect on proliferation resistance from a terrorist viewpoint. However, this option may have major impacts on safeguards, measurements and on facility operating procedures and costs.

2. Increase the thermal flux of the fissile material such that the explosive compounds necessary to ignite the fission weapons would decompose before the weapons could be used.

Add an element to the fuel meat whose irradiation product would follow the plutonium through the separation and purification process that would raise the thermal flux. For plutonium, only isotopes that generate ${ }^{238} \mathrm{Pu}$ could possibly fit this requirement.

Extensive ORIGIN analyses and extensive bomb calculations would be necessary to determine if it is possible to raise the ${ }^{238} \mathrm{Pu}$ content high enough decompose the high explosive prior to ignition of the weapon. Whereas it is conceivable that sufficient ${ }^{238} \mathrm{Pu}$ might be bred into the fuel to prevent the stockpiling of weapons, arming a weapon at the last possible minute might allow the high explosive to be stable for a sufficient time to ignite the weapon. Therefore, this has primarily nuisance value; it is not a serious deterrent although it might create significant design constraints and handling problems.

3. Isotopically dilute the fissile element so that the fissile element would no longer yield a nuclear explosion.

Unlike uranium that has both fissile and fertile isotopes, all isotopes 
of plutonium are fissile. As a result, increasing the concentration of the even isotopes of plutonium does increase the amount necessary for a weapon, and they may increase the difficulty of fabricating and delivering the weapon; however, this does not render the plutonium non-usable in a weapon. The major benefit of isotopic dilution of plutonium is that perhaps additional spent fuel rods would have to be stolen and processed, increasing the likelihood of detection. Also, the time necessary to process a significant quantity of plutonium to fabricate a weapon would likely increase.

In summary, markedly enhancing proliferation resistance from a purely physics viewpoint has a low probability of success, given the scenarios considered here. It is, however, possible to reduce the amount of plutonium that would be produced in a reactor by using both ${ }^{238} \mathrm{U}$ and ${ }^{232} \mathrm{Th}$ as the fertile isotopes.

The major impact of this latter option would be to increase the number of fuel elements that must be stolen to yield a significant quantity of plutonium. The added amount of processing required and the extra difficulty of processing fuel containing Th, $\mathrm{U}$, and $\mathrm{Pu}$ would add precious time required to recover and purify a significant quantity of plutonium.

Finally, it is clear that novel schemes need to be considered and developed if the physics-based approach is to be effective in deterring the misuse of spent fuel rods. Success in this area would constitute an intrinsic, or engineering, rather than an extrinsic solution to this thorny problem and would substantially ensure the security of the nuclear energy cycle for peaceful applications.

\section{Self-Protecting From a Chemistry Perspective}

There are several theoretical methods that may be used to make spent fuel more proliferation resistant:

1. Add an element to the fuel meat whose irradiation product would follow the plutonium through the separation and purification process that would either:

a. Raise the radiation dose of the plutonium product far above the low (1 Sv/hr) IAEA threshold for self-protecting

b. Interfere with the machining of a weapon

c. Interfere with the detonation of a weapon

- As a result of the unique chemistry of plutonium, there are no isotopes that would both follow the plutonium through the purification process and add additional radiation that even approaches the low (1 Sv/hr) IAEA threshold for self-protection.

- Of all the elements that might interfere with machining or detonation, only ${ }^{238} \mathrm{Pu}$ would actually follow plutonium through the purification 
process. This isotope can be generated in the fuel meat by adding either ${ }^{237} \mathrm{~Np}$ or ${ }^{241} \mathrm{Am}$. Adding ${ }^{237} \mathrm{~Np}$ would generate ${ }^{238} \mathrm{Pu}$ in the shortest time but would burn out more quickly. Since ${ }^{241}$ Am irradiation first generates ${ }^{242} \mathrm{Cm}$, which decays to ${ }^{238} \mathrm{Pu}$, it would take a longer time frame to generate the ${ }^{238} \mathrm{Pu}$. Therefore a combination or ${ }^{237} \mathrm{~Np}$ and ${ }^{214} \mathrm{Am}$ would be more beneficial.

As discussed above, this approach adds primarily nuisance value; it is not a serious deterrent although it might create significant design constraints and handling difficulties.

2. Add an element to the fuel cladding or prepare the fuel form in such a way that would interfere with exposing the fuel meat to the process solution. It is not necessary to dissolve the fuel cladding to expose the fuel meat to the dissolution solvent, be it aqueous or molten salt.

- For Savannah River plutonium production targets, the target meat was clad in aluminum; this cladding was simply dissolved in a solution of $\mathrm{NaOH}-\mathrm{NaNO}_{3}$.

- France and England used MAGNOX fueled reactors; these fuel elements were mechanically decladded.

- Savannah River removed the stainless steel cladding of fuel elements using an electrolytic dissolver to dissolve the stainless steel.

- On a commercial scale, the Zircaloy clad fuel is simply sheared into small pieces to expose the fuel meat.

Simply adding any element to the cladding to interfere with exposing the fuel meat is ineffective.

Changing the shape of the fuel does have an effect on the method of exposure of the fuel meat. For instance, the Pebble Bed reactor uses tennis ball-sized pebbles that are made of pyrolytic graphite (which acts as the moderator), and they contain thousands of micro fuel particles called TR1SO particles. These TRISO fuel particles consist of a fissile material (such as ${ }^{235} \mathrm{U}$ ) surrounded by a coated ceramic layer of SiC for structural integrity. These "pebbles" would have to be ground, perhaps in a ball mill or rod mill, to expose the fuel meat. It might be beneficial to remove the pyrolytic graphite. As a result of the density differences between pyrolytic graphite and the fuel particles, sluicing could possibly do this.

3. Add an element to the fuel meat whose irradiation product would interfere with the recovery and purification process:

- Make dissolution in the recovery medium very difficult

- Interfere with the separation processes, i.e., emulsify the solvent 


\section{Interference with Purification Processes}

Basically, there are two methods to interfere with the aqueous/organic purification processes. One is the introduction of an emulsifier to emulsify the solvent; the other is to add something that would plug the ion exchange columns. Silica fills the bill for both of these. Silica is the activation product of aluminum. However, silica is easily removed from aqueous solutions. If large amounts of silica are present, simple digestion will coagulate the silica and it can be removed via centrifugation. If smaller amounts are present, gelatin can be added prior to digestion - the coagulated silicagelatin is then removed via centrifugation.

\section{REACTOR OPERATIONS}

When a reactor is operating, a vast number of reactions are happening. When fresh fuel is added to the reactor the first set of reactions are the generation of ${ }^{236} \mathrm{U},{ }^{238} \mathrm{Pu}$. and ${ }^{239} \mathrm{Pu}$ via the reactions:

$$
\begin{aligned}
& { }^{235} U(n, \gamma){ }^{236} U \stackrel{2.42 \times 10^{7} \text { years }}{\longrightarrow}{ }^{232} \mathrm{Th} \\
& { }^{235} U(n, \gamma)^{237} \mathrm{U} \longrightarrow{ }^{237} \mathrm{~Np}(n, \gamma)^{238} \mathrm{Pu} \stackrel{\text { 84.7years }}{\longrightarrow}{ }^{234} \mathrm{U} \\
& { }^{238} \mathrm{U}(n, \gamma)^{239} \mathrm{~Np} \stackrel{2.35 \text { days }}{\longrightarrow}{ }^{239} \mathrm{Pu} \stackrel{24,390 \text { years }}{\longrightarrow}{ }^{235} U
\end{aligned}
$$

As the irradiation proceeds, the isotopes ${ }^{236} \mathrm{U},{ }^{238} \mathrm{Pu}$, and ${ }^{239} \mathrm{Pu}$ build up in the fuel meat. But these isotopes also react with neutrons; ${ }^{236} \mathrm{U}$ and ${ }^{238} \mathrm{Pu}$ capture neutrons. The ${ }^{239} \mathrm{Pu}$ can either fission to yield fission products or capture a neutron to become ${ }^{240} \mathrm{Pu}$. Hence the new sets of reactions that are occurring are:

$$
\begin{aligned}
& { }^{236} \mathrm{U}(n, \gamma){ }^{237} \mathrm{~Np} \stackrel{2.14 x 10^{6} \text { years }}{\longrightarrow}{ }^{233} \mathrm{~Pa} \\
& { }^{238} \mathrm{Pu}(n, \gamma){ }^{239} \mathrm{Pu} \stackrel{24,390 \text { years }}{\longrightarrow}{ }^{235} \mathrm{U} \\
& { }^{239} \mathrm{Pu}(n, \gamma){ }^{240} \mathrm{Pu} \stackrel{\text { 6,600years }}{\longrightarrow}{ }^{236} \mathrm{U}
\end{aligned}
$$

The new isotopes that build up from these reactions are ${ }^{237} \mathrm{~Np}$ and ${ }^{240} \mathrm{Pu}$. These isotopes, in turn, can absorb a neutron to yield ${ }^{238} \mathrm{Pu}$ and ${ }^{241} \mathrm{Pu}$ via the reactions:

$$
\begin{aligned}
& { }^{237} \mathrm{~Np}(n, \gamma){ }^{238} \mathrm{~Np} \stackrel{2.12 \text { days }}{\longrightarrow}{ }^{238} \mathrm{Pu} \\
& { }^{240} \mathrm{Pu}(n, \gamma){ }^{241} \mathrm{Pu} \stackrel{14.3 \text { years }}{\longrightarrow}{ }^{241} \mathrm{Am}
\end{aligned}
$$

The new isotopes that build up from these reactions are ${ }^{241} \mathrm{Am}$ and ${ }^{241} \mathrm{Pu}$. These isotopes, in turn, can absorb a neutron to yield ${ }^{242} \mathrm{Cm}$ (which decays to ${ }^{238} \mathrm{Pu}$ ) and ${ }^{242} \mathrm{Pu}$ via the reactions:

$$
{ }^{241} \mathrm{Am}(n, \gamma)^{242} \mathrm{Am} \underset{\beta^{-}(84 \%)}{\stackrel{16 \text { hours }}{\longrightarrow}}{ }^{242} \mathrm{Am} \stackrel{162.9 \text { days }}{\longrightarrow}{ }^{238} \mathrm{Pu}
$$


${ }^{241} \mathrm{Pu}(n, \gamma){ }^{242} \mathrm{Pu} \stackrel{3.87 \times 10^{5} \text { years }}{\longrightarrow}{ }^{238} \mathrm{U}$

The isotope ${ }^{241} \mathrm{Pu}$ can also fission in the reactor yielding both heat and fission products. The isotope ${ }^{242} \mathrm{Pu}$ can absorb a neutron to generate ${ }^{243} \mathrm{Pu}$. However, ${ }^{243} \mathrm{Pu}$ has only a $4.96-$ hour half-life. As a result it is ${ }^{243} \mathrm{Am}$ that builds up in the fuel, not ${ }^{243} \mathrm{Pu}$. This occurs via the reactions:

${ }^{242} \mathrm{Pu}(n, \gamma){ }^{243} \mathrm{Pu} \stackrel{4.96 \text { hours }}{\longrightarrow}{ }^{243} \mathrm{Am}$

In turn, the ${ }^{243} \mathrm{Am}$ can absorb a neutron to generate ${ }^{244} \mathrm{Am}$, which has a 10.1 -hour half-life, decaying to ${ }^{244} \mathrm{Cm}$.

Eventually the fission products building up in the reactor begin to absorb enough neutrons to make the operation of the reactor unprofitable, and new fuel must then be inserted. The ${ }^{239} \mathrm{Pu}$ and ${ }^{241} \mathrm{Pu}$ isotopes build up to a point that approximately half of the heat in the reactor is generated via the fission of plutonium.

When the spent fuel is removed from the reactor, it contains a mixture of fission products, primarily the actinides ${ }^{235} \mathrm{U},{ }^{236} \mathrm{U},{ }^{237} \mathrm{~Np},{ }^{238} \mathrm{Pu},{ }^{239} \mathrm{Pu},{ }^{240} \mathrm{Pu},{ }^{241} \mathrm{Pu},{ }^{242} \mathrm{Pu},{ }^{241} \mathrm{Am},{ }^{243} \mathrm{Am}$, ${ }^{242} \mathrm{Cm}$ and ${ }^{244} \mathrm{Cm}$. Once separated and purified, the primary heat sources in the plutonium are ${ }^{238} \mathrm{Pu}$ and ${ }^{241} \mathrm{Pu}$; the primary neutron sources from spontaneous fission are the even isotopes: ${ }^{238} \mathrm{Pu},{ }^{240} \mathrm{Pu}$, and ${ }^{242} \mathrm{Pu}$. The most desirable isotopes for a weapon are the two odd isotopes: ${ }^{239} \mathrm{Pu}$ and ${ }^{241} \mathrm{Pu}$.

As a final observation, we note that the incorporation of isotopes to the fuel that will transform into the primary heat generating isotopes would make the recovered plutonium less desirable for weapons. Therefore, the most promising isotopes to add either to fresh uranium fuel or to MOX fuel are ${ }^{237} \mathrm{~Np}$ and ${ }^{241} \mathrm{Am}$.

\section{Burnable Poisons}

Attainment of high burn-up of nuclear fuels in a reactor involves substantial difficulties and complexities in controlling fuel consumption. To simplify controlling the reactor, fuel manufactures typically add burnable poisons (a substance with a large neutron cross-section) to the fresh fuel. Typical examples are boron, gadolinium, and hafnium. If a burnable poison can be added that yields a long-lived isotope that would give a sufficient dose rate, then the time that the fuel would be self protecting would be lengthened. Actinide isotopes are not generally thought of as burnable poisons, however in this application, they might be useful.

\section{Curium Isotopes}

Curium isotopes are generated in spent fuel through neutron capture by americium isotopes. The only curium isotope with a sufficiently long half-life, and a high enough gamma radiation dose rate to affect the dose of the spent fuel is ${ }^{243} \mathrm{Cm}$. If sufficient ${ }^{243} \mathrm{Cm}$ could be generated within the spent fuel, it could keep the dose at a higher rate in the first 50 or so years of cooling. Its calculated gamma dose rate is 6 $\mathrm{Sv} / \mathrm{hr}-\mathrm{kg}$. However, only three curium isotopes $\left({ }^{242} \mathrm{Cm},{ }^{244} \mathrm{Cm}\right.$, and $\left.{ }^{248} \mathrm{Cm}\right)$ are available in 
quantities sufficient for chemical studies - certainly not enough to place into fresh long burn-up fuel as a burnable poison. This isotope has a half-life of 28.5 years but its precursor is ${ }^{242} \mathrm{Cm}$ with a half-life of only 162.9 days. Even if sufficient amounts of ${ }^{242} \mathrm{Cm}$ could be generated (by addition of ${ }^{241} \mathrm{Am}$ to the fuel), most of the ${ }^{242} \mathrm{Cm}$ would decay to ${ }^{238} \mathrm{Pu}$ rather than absorbing a neutron to yield sufficient amounts of ${ }^{243} \mathrm{Cm}$ to keep the fuel above the IAEA threshold.

\section{Americium Isotopes}

Americium isotopes are generated in spent fuel via the reactions:

$$
\begin{aligned}
& { }^{239} \mathrm{Pu}(n, \gamma){ }^{240} \mathrm{Pu}(n, \gamma)^{241} \mathrm{Pu} \stackrel{14.3 \text { years }}{\beta^{-}}{ }^{241} \mathrm{Am} \\
& { }^{242} \mathrm{Pu}(n, \gamma)^{243} \mathrm{Pu} \stackrel{\text { 5hours }}{\beta^{-}}{ }^{243} \mathrm{Am}
\end{aligned}
$$

Even though both of these isotopes build up in the fuel, neither of these isotopes have a sufficient dose rate to keep the spent fuel self-protecting.

${ }^{241} \mathrm{Am}$, however, does have an interesting twist that might be useful. Neutron irradiation of ${ }^{241} \mathrm{Am}$ at an intermediate flux level produces ${ }^{242} \mathrm{Cm}$ and then ${ }^{238} \mathrm{Pu}$ via the reactions:

$$
{ }^{241} \mathrm{Am}(n, \gamma){ }^{242} \mathrm{Am} \underset{\beta^{-}(84 \%)}{\stackrel{16 \text { hours }}{\longrightarrow}} 242 \mathrm{Am} \underset{\alpha}{\stackrel{162.9 \text { days }}{\longrightarrow}}{ }^{238} \mathrm{Pu}
$$

Although this would not raise the gamma dose rate sufficiently to make the fuel selfprotecting, it would raise the thermal flux from the recovered and purified plutonium. If MOX fuel were prepared from well-aged fuels-grade plutonium oxide, the ${ }^{238} \mathrm{Pu}$ content of the spent MOX fuel could be in the 5 to $9 \%$ range. Adding sufficient ${ }^{241} \mathrm{Am}$ to bring the ${ }^{238} \mathrm{Pu}$ content of the spent fuel up to about $10 \%$ would increase the thermal flux to about 55 to 60 watts per kilogram. The thermal flux from weapons-grade plutonium is about 2.3 watts per $\mathrm{kg}$; the thermal flux from typical reactor grade plutonium is about 20 watts per kg.

Assessing relevant pathways and the 162.9 -day half-life, ${ }^{242} \mathrm{Cm}$ would take some time to build up in the reactor. It would take months of irradiation before there was a significant amount of ${ }^{238} \mathrm{Pu}$ generated. Calculations would be necessary to determine the exact timing and amount of ${ }^{238} \mathrm{Pu}$ that could be generated.

A number of things are happening simultaneously in the reactor. The isotope ${ }^{241} \mathrm{Pu}$ is being generated via neutron capture by ${ }^{240} \mathrm{Pu}$. At the same time ${ }^{241} \mathrm{Pu}$ is being depleted via the following:

- Fission of ${ }^{241} \mathrm{Pu}$ to heat and fission products

- Neutron capture by ${ }^{241} \mathrm{Pu}$ to generate ${ }^{242} \mathrm{Pu}$

- Decay of ${ }^{241} \mathrm{Pu}$ to generate ${ }^{241} \mathrm{Am}$. 
Calculations could be performed to determine the ${ }^{241} \mathrm{Pu},{ }^{241} \mathrm{Am}$, and ${ }^{238} \mathrm{Pu}$ content with time.

\section{Neptuninm-237}

The addition of ${ }^{237} \mathrm{~Np}$ (half-life $2.14 \times 10^{6}$ years) to the fuel would do nothing to enhance the radiation protection of the spent fuel. However, the neutron activation product of ${ }^{237} \mathrm{~Np}$ is ${ }^{238} \mathrm{Pu}$ via the reactions:

$$
{ }^{237} \mathrm{~Np}(n, \gamma){ }^{238} \mathrm{~Np} \stackrel{\stackrel{2.12 \text { days }}{\longrightarrow}{ }^{-}}{238} \mathrm{Pu}
$$

With such a short half-life, ${ }^{238} \mathrm{Pu}$ would begin to build up in the fuel meat in just a few days. Here, as with ${ }^{241} \mathrm{Am}$ described above, the ${ }^{237} \mathrm{~Np}$ would act as a neutron poison to help control the reactor in the early days of new fuel irradiation. Calculations could be performed to determine the ${ }^{238} \mathrm{Pu}$ concentration with time.

\section{Americium-241 Mixed with Neptunium-237}

Adding a mixture of ${ }^{237} \mathrm{~Np}$ and ${ }^{241} \mathrm{Am}$ could possibly raise the ${ }^{238} \mathrm{Pu}$ content of the spent fuel to about $17 \%$ and possibly as high as $20 \%{ }^{238} \mathrm{Pu}$ [Chang 2008]. As discussed above, the ${ }^{237} \mathrm{~Np}$ and ${ }^{241} \mathrm{Am}$ would act not only as a source of ${ }^{238} \mathrm{Pu}$, but also as direct contributors to the reactivity control of the system to which they were added.

\section{MOX Fuels}

Perhaps the most straightforward method to assure high ${ }^{238} \mathrm{Pu}$ content in the spent fuel is to use recycled LWR plutonium. At present, Avera in France is using fresh LWR recovered and purified plutonium to prepare MOX fuel. However, many years of $\mathrm{PuO}_{2}$ production product have been stored. At the time of removal from the reactor, the overall isotopic content, of course, depends upon the burn-up characteristics (see Table II).

\begin{tabular}{|l|l|l|l|l|l|}
\hline \multicolumn{7}{|c|}{ Table II.Typical plutonium isotopics } \\
\hline Type & ${ }^{238} \mathrm{Pu}(\%)$ & ${ }^{239} \mathrm{Pu}(\%)$ & ${ }^{240} \mathrm{Pu}(\%)$ & $\begin{array}{l}{ }^{241} \mathrm{Pu}(\%) \\
\text { Ref. 17 }\end{array}$ & ${ }^{242} \mathrm{Pu}(\%)$ \\
\hline Magnox & Negligible & 65 & 25 & 5 & 1 \\
\hline Reactor-grade 33 GWd/t & 1.3 & 60.3 & 24.3 & 9.1 & 5 \\
\hline Reactor-grade 42 GWd/t & 2 & 55 & 23 & 12 & 5 \\
\hline $\begin{array}{l}\text { Reactor-grade LWR 52 } \\
\text { GWd/t }\end{array}$ & 2 & 53 & 25 & 15 & 5 \\
\hline Reactor-grade 50 GWd/t & 2.7 & 47 & 26 & 15 & 9 \\
\hline MOX grade & 1.9 & 40.4 & 32.1 & 17.8 & 7.8 \\
\hline
\end{tabular}

\footnotetext{
${ }^{17}$ This is actually the sum of ${ }^{241} \mathrm{Pu}$ and ${ }^{241} \mathrm{Am}$. At the higher burn-ups, some of the ingrown ${ }^{241} \mathrm{Pu}$ will have decayed to ${ }^{241} \mathrm{Am}$. When removed from the reactor, the sum of the ${ }^{241} \mathrm{Pu}$ plus ${ }^{241} \mathrm{Am}$ is fixed, but the ratio of ${ }^{241} \mathrm{Am}$ to ${ }^{241} \mathrm{Pu}$ will increase with time.
} 
If MOX fuels were fabricated with plutonium that had been aged for 14 years, the ${ }^{241} \mathrm{Am}$ would approximately equal the ${ }^{241} \mathrm{Pu}$. As a result, the weapons desirable isotopes, ${ }^{239} \mathrm{Pu}$ plus ${ }^{241} \mathrm{Pu}$, would be reduced from $\sim 67-69 \%$ to $\sim 60-63 \%$; the weapons undesirable plutonium isotopes, ${ }^{238} \mathrm{Pu},{ }^{240} \mathrm{Pu}$, and ${ }^{242} \mathrm{Pu}$, would be $\sim 30$ $32 \%$ and the ${ }^{241} \mathrm{Am} \sim 6-8 \%$. If ${ }^{237} \mathrm{~Np}$ were added to this mixture, then upon irradiation:

- The ${ }^{238} \mathrm{Pu}$ would be increasing with time from the floor of about $2 \%$,

- The ${ }^{240} \mathrm{Pu}$ content would be expected to top out at about $40 \%$

- The ${ }^{241} \mathrm{Pu}$ and ${ }^{242} \mathrm{Pu}$ would be expected to increase with burn-up,

- The ${ }^{239} \mathrm{Pu}$ content would continue to decrease with burn-up.

Calculations would be necessary to determine:

- The amount of ${ }^{237} \mathrm{~Np}$ that should be added to the mix

- The amount of recycled plutonium that should be added to the fuel

- Whether or not additional ${ }^{24 \mathrm{I}} \mathrm{Am}$ should be added to the mix

- The isotopics of the spent MOX fuel fabricated from this master blend of isotopes.

Calculations would also be necessary to determine the amount of plutonium from the spent MOX fuel that would be necessary to fabricate a weapon.

\section{Protactinium-231}

Protactinium as ${ }^{231} \mathrm{~Pa}$ (half-life 34,000 years) occurs in pitchblende, but even the richest ores contains only about 1 part in $10^{7}$. It is the first decay daughter of ${ }^{235}$ U.The isolation of protactinium from its minerals is difficult but doable. Under neutron irradiation, ${ }^{231} \mathrm{~Pa}$ is converted into ${ }^{232} \mathrm{U}$ (half-life 69 Years). High-energy gammaradiation of ${ }^{232} \mathrm{U}$ is emitted by its decay products; ${ }^{232} \mathrm{U}$ decays with a 69 year half-life through 1.9 year half-life ${ }^{228} \mathrm{Th}$ to ${ }^{208} \mathrm{Tl}$, which emits a $2.6 \mathrm{MeV}$ gamma ray upon decay. After 2 years of decay ${ }^{208} \mathrm{Tl}$ accounts for about $85 \%$ of the total dose [Schupp 1960; Sampson 2001].

Calculations would be required to determine the correct amount of ${ }^{231} \mathrm{~Pa}$ to add to the fuel prior to irradiation. If that amount of ${ }^{231} \mathrm{~Pa}$ could be tolerated in the reactor (and sufficient stocks of ${ }^{231} \mathrm{~Pa}$ could be obtained), then the combination of ${ }^{231} \mathrm{~Pa}$ daughterproducts and the normal fission products might possibly extend the time in which the spent fuel was self-protecting to much greater than 100 years.

However, the resulting ${ }^{232} \mathrm{U}$ would follow the uranium through any of the known plutonium purification cycles (precipitation, solvent extraction, or ion exchange techniques). At best, ${ }^{232} \mathrm{U}$ would add only to the self-protection of the spent fuel- not the extracted plutonium. 


\section{Stable Elements}

A variety of elements whose neutron activation products are highly active could possibly be added to the fuel. The half-lives would have to be long enough, yet short enough, to provide a high dose over an extended period of time. Elements that have been proposed in the past include ${ }^{197} \mathrm{Au},{ }^{181} \mathrm{Ta},{ }^{64} \mathrm{Zn}$, and ${ }^{59} \mathrm{Co}$. Gold, however, would provide a high dose for only a few days. Tantalum and zinc would provide a high dose for a few months. ${ }^{60} \mathrm{Co}$ (the neutron activation product of ${ }^{59} \mathrm{Co}$ ) would provide additional radiation dose, at most, for a decade or so. As a result of the unique chemistry of plutonium, these elements would not follow the plutonium through any of the known purification cycles. Therefore at best, these would add only to the self-protection of the spent fuel. With the exception of ${ }^{60} \mathrm{Co}$, the added protection would be restricted, at most, to the early days of the cooling cycle and therefore would probably not justify the effort.

\section{Cobalt}

A fictional doomsday bomb, made popular by Neville Shute's 1957 novel, and subsequent 1959 movie, On the Beach, the cobalt bomb was a hydrogen bomb with a jacket of ordinary cobalt metal. During the explosion, the cobalt metal would be transmuted via neutron bombardment into the isotope ${ }^{60} \mathrm{Co}$. This isotope, with a half-life of 5.27 years, is a very strong emitter of gamma rays as it undergoes beta decay to an excited state and which then relaxes to the ground state of ${ }^{60} \mathrm{Ni}$, thereby releasing gamma radiation. The short half-life and the intensity of the radioactivity caused Leo Szilard to suggest that such bombs could wipe out all life on earth.

NOTE: One gram of ${ }^{60} \mathrm{Co}$ contains approximately fifty curies of radioactivity. Held at close range, this amount of ${ }^{60} \mathrm{Co}$ would irradiate a person with approximately 0.5 gray of ionizing radiation per minute. A prompt, full body dose of approximately three to four grays would kill approximately $50 \%$ of the exposed population within thirty days; at this dose rate, the $\mathrm{LD}_{50}$ dose could be accumulated in just a few minutes. However, for Szilard's concept to work, it would require a weapon containing 510 tons of cobalt to spread a theoretical even dosing of 1.0 gram of ${ }^{60} \mathrm{Co}$ per square kilometer of the Earth's surface.

Inspired by Szilard's warnings, science fiction authors and Hollywood have made cobalt bombs the doomsday weapons in their works:

- Staney Kubrick further popularized the cobalt bomb as a "Doomsday Device" in the 1964 film Dr. Strangelove or: How I Learned to Stop

Worrying and Love the Bomb.

- The Sum of All Fears by Tom Clancy

- Goldfinger by Ian Fleming

- Beneath the Plaent of the Apes (film directed by Ted Post)

- Etc.

The neutron-activated cobalt supposedly would have maximized the environmental 
damage from the radioactive fallout. In the first few hours after detonation, the gamma radiation produced by the fission products would be more intense than that produced by the neutron activated ${ }^{60} \mathrm{Co}$. Since the majority of the fission products have half-lives less than a year, many less than an hour, at one year the dose from the ${ }^{60} \mathrm{Co}$ is greater than from the remaining fission products by nearly an order of magnitude. However, after about 10 years, the two fission-product pairs, ${ }^{90} \mathrm{Sr}-{ }^{90} \mathrm{Y}$ and ${ }^{137} \mathrm{Cs}-{ }^{137 \mathrm{~m}} \mathrm{Ba}$, are the primary dose rate contributors; their half-lives are 28 and 30 years, respectively. Because of the short half-life of ${ }^{60} \mathrm{Co}$ (5.27 years), the dose from the fission products would be greater than that from the ${ }^{60} \mathrm{Co}$ after a few decades.

Calculations would be required to determine the correct amount of ${ }^{59} \mathrm{Co}$ to add to the fuel prior to irradiation. If that amount of ${ }^{59} \mathrm{Co}$ could be tolerated in the reactor, then the combination of ${ }^{60} \mathrm{Co}$ and the normal fission products might possibly extend the time in which the spent fuel was self-protecting.

Unfortunately, ${ }^{60} \mathrm{Co}$ would not follow the plutonium through any of the known plutonium purification cycles (precipitation, solvent extraction, or ion exchange techniques). And at best, ${ }^{60} \mathrm{Co}$ would add only to the self-protection of the spent fuel.

\section{Increasing the isotopic ratio of ${ }^{238} \mathrm{Pu} / \mathrm{Pu}$}

There are two major approaches to enhance the proliferation resistance of plutonium from a power reactor:

- Increase the burn-up in the discharged fuel

- Use of transuranic nuclides $\left({ }^{237} \mathrm{~Np}\right.$ and $\left.{ }^{241} \mathrm{Am}\right)$ in the high burn-up fuel.

Both methods will drastically increase the proliferation resistance isotope ratio of ${ }^{238} \mathrm{Pu} / \mathrm{Pu}$. The use of ${ }^{237} \mathrm{~Np}$ and ${ }^{241} \mathrm{Am}$ also serve burnable poisons to hold-down the initial reactivity of the fuel.

Based on criticality mass considerations, the ${ }^{235} \mathrm{U}$ enrichment limit for proliferation resistance is $20 \%$. However, unlike uranium, any isotopic mixture of plutonium has a finite bare critical mass. Hence, there is no general isotopic concentration threshold for plutonium isotopes from a criticality point-of-view. Nevertheless, the suitability for weapons usage varies significantly amongst plutonium isotopes. Mark [Mark 1993] lists the important characteristics of plutonium isotopes. Plutonium-238, ${ }^{240} \mathrm{Pu}$ and ${ }^{242} \mathrm{Pu}$ have high spontaneous neutron generation, which reduces the bomb yield significantly. Plutonium-238 also has high decay heat, which also complicates the design of the weapon. Addition of sufficien ${ }^{237} \mathrm{~Np}$ and ${ }^{241} \mathrm{Am}$ into high burn-up fuel can vastly increase the ${ }^{238} \mathrm{Pu} / \mathrm{Pu}$ ratio and thereby enhance the proliferation resistance.

Chang [Chang 2008] has shown in a study of high burn-up LEU fuel that the ${ }^{238} \mathrm{Pu}$ content of discharged fuel can be raised to the $15-19 \%{ }^{238} \mathrm{Pu}$ range by the addition of ${ }^{237} \mathrm{~Np}$ and ${ }^{241} \mathrm{Am}$. 


\section{Conclusion}

Global appetite for fission power is projected to grow dramatically this century, and for good reason. Despite considerable research to identify new sources of energy, fission remains the most plentiful and practical alternative to fossil fuels. The environmental challenges of fossil fuel have made the fission power option increasingly attractive, particularly as we are forced to rely on reserves in ecologically fragile or politically unstable corners of the globe. Caught between a globally eroding fossil fuel reserve as well as the uncertainty and considerable costs in the development of fusion power, most of the world will most likely come to rely on fission power for at least the remainder of the $21^{\text {st }}$ century.

Despite inevitable growth, fission power faces enduring challenges in sustainability and security. One of fission power's greatest hurdles to universal acceptance is the risk of potential misuse for nefarious purposes of fissionable byproducts in spent fuel, such as plutonium. With this issue in mind, we have discussed intrinsic concepts in this report that are motivated by the premise that the utility, desirability, and applicability of nuclear materials can be reduced. In a general sense, the intrinsic solutions aim to reduce or eliminate the quantity of existing weaponsusable material; avoid production of new weapons-usable material through enrichment, breeding, extraction; or employ engineering solutions to make the fuel cycle less useful or more difficult for producing weapons-usable material.

By their nature, these schemes require modifications to existing fuel cycles. As such, the concomitants of these modifications require engagement from the nuclearreactor and fuel-design community to fully assess their effects. Unfortunately, active pursuit of any scheme that could further complicate the spread of domestic nuclear power will probably be understandably unpopular. Nevertheless, the nonproliferation and counterterrorism issues are paramount, and we posit that the exploration, development, and implementation of intrinsic mechanisms such as discussed here are part of a balanced approach aimed at preventing the misuse of nuclear material for nuclear-energy applications. 


\section{References}

[Bathke 2009] Bathke, C.G., Ebbinghaus, B.B., Sleaford, B.W., Wallace, R.K., Collins, B.A., Hase, K.R., Jarvinen, G.D., Bradley, K.S., Ireland, J.R., Johnson, M.W., Prichard, A.W., and Smith, B.W., "The Attractiveness of Materials in Advanced Nuclear Fuel Cycles for Various Proliferation and Theft Scenarios," Proceedings of Global 2009, Paris, France, September 6-11, 2009, Paper 9543.

[[Chang 2008] Chang, G.S., "Enhancing BWR Proliferation Resistance Fuel with Minor Actinides," Plutonium Futures-The Science 2008, A Topical Conference on Plutonium and Actinides, Dijon, France, July 7-11, 2008.

Coates, 2005] "Radiation Effects on Personnel Performance Capability and a Summary of Dose Levels for Spent Research Reactor Fuels," Coates, C.W., Broadhead, B.L., Krichinsky, A.M., Leggett, R.W., Emmett, M.B., and Hines, J.B., Oakridge National Laboratory, Report ORNL/TM-2005/261, December 2005.

[Feiveson 1979] Science 26 January 1979, Vol. 203 no. 4378 pp. 330-337.

[INFCIRC/225/Rev.4 1979] "The Physical Protection of Nuclear Material and Nuclear Facilities," INFCIRC/225/Rev. 4, International Atomic Energy Agency, (Austria, June 1999)

[Kang 2005] Kang, J., and von Hippel, F., "Limited Proliferation-Resistance Benefits from Recycling Unseparated Transuranics and Lanthanides from Light-Water Reactor Spent Fuel," Science and Global Security, 13: 169-181, 2005.

[Kibriyama 2000] Kiriyama, E. and Pickett, S., "Non-Proliferation Criteria for Nuclear Fuel Cycle Options," Progress in Nuclear Energy, Vol. 37, No. 1-4, pp. 71-76, 2000.

[Mark 1993] Mark, J.C., "Explosive Properties of Reactor-Grade Plutonium,” Science \& Global Security, 1993, V4, pp. 111-128.

[Pilat 2009] Pilat, J.F., "Proliferation Resistance: Issues, Initiatives, and Evaluations," Global 2009 International Conference, Paris, France, September 6-11, 2009.

[Pond 1994] Pond, R.B., and Matos, J.E., "Photon Dose Rates from Spent Fuel Assemblies with Relation to Self-Protection," International Meeting on Reduced Enrichment for Research and Test Reactors, Paris, France, Sept. 18-21, 1994.

[ Pond 1996] Pond, R.B., and Matos, J.E., "Photon Dose Rates from Spent Fuel Assemblies with Relation to Self-Protection (Rev. 1)," Report ANL/RERTR/TM-25, Argonne National Laboratory, Argonne, IL 60439, Feb. 1996.

[Purex Process 1977] Starks, J. B. "The Purex Process," Savannah River Plant, Report no. DPSPU 77-11-1, January 1977. 
[Sampson, 2001] Sampson, T.E., and Cremers, T.L., "The Concentration of ${ }^{236} \mathrm{Pu}$ Daughters in Plutonium for Application to MOX Production from Plutonium from Dismantled US Nuclear Weapons," Report LA-13762-MS, Los Alamos National Laboratory, May 2001.

[Schupp, 1960] Schupp, G., Daniel, H., Eakins, G.W., Jensen, E.N., “Transition Intensities in the ${ }^{208} \mathrm{Tl}$ Beta Decay, the ${ }^{212} \mathrm{Bi} \rightarrow{ }^{212} \mathrm{Po}$ Decay Scheme, and the ${ }^{212} \mathrm{Bi}$ Branching Ratio, Physical Review, V120, No. 1, pp. 189-198 (1960).

[Wright 2000] Wright, R.Q., Jordan, W.C., and Westfall, R.M., "Critical Masses of Bare Metal Spheres Using SCALE/XSDRN," Proceedings of the International Conference on Nuclear Criticality '99 (ICNC '99), p. 1476 (September, 1999). 